\title{
Striving and Thriving in a Foreign Culture: A Mixed Method Approach on Adult International Students' Experience in U.S.A.
}

\author{
Dianbing Chen ${ }^{1} \&$ Xinxiao Yang ${ }^{2}$ \\ ${ }^{1}$ University of Wyoming, USA \\ ${ }^{2}$ Zhejiang Normal University, P.R. China \\ Correspondence: Dianbing Chen, University of Wyoming, USA
}

Received: February 21, 2014

Accepted: March 12, $2014 \quad$ Online Published: May 5, 2014

doi:10.11114/jets.v2i3.353

URL: http://dx.doi.org/10.11114/jets.v2i3.353

\begin{abstract}
In this mixed method study, we examined the experience of a sample of international students in four American universities to identify the factors that might enhance their ability in surviving and thriving in a foreign country within the context of university internationalization. The research explored the concepts of cultural values, behaviors, perceptions, and strategies related to international students' cultural adaption. The findings of this study indicate that while benefiting from the oversea study experience, international students faced a number of challenges associated with their unique and unfamiliar surroundings. Moreover, this research suggests that while personal and psychological factors are important in the process of being successful in American universities, the availability of supportive resources on campus and community are also critical. The recommendations for university faculty and staff were discussed.
\end{abstract}

Keywords: mixed method; university internationalization; international students' experience; thriving and surviving skills

\section{Introduction}

With more and more international students pursuing their higher academic degrees in the United States than in any other country, the late 20th and early 21th centuries have witnessed unprecedented growth in international students' enrollment at American universities and colleges (Carswell, 2010). As NCES (National Center for Educational Statistics, 2009) reported, in the past 20 years the number of international students has more than doubled from 311,880 in 1988 to 671,616. Also, the 2011 Open Doors data reports showed that total international students enrollment in the U.S. increased 5\% in 2010/11 to a record high of 723,277 international students. The reports also indicated that international students contributed over $\$ 21.2$ billion to the U.S. economy in 2012 and $63 \%$ of international students (81\% at the undergraduate level) rely primarily upon personal and family funds to pay for their studies. It is obvious that the growth of the number of international students and the contributions they have made to the U. S. greatly impacts higher education.

While being exposed to different cultural environments and encounters with different people, international students need to learn to manage all the challenges related to coming to a new country and culture. However, certain cultural beliefs and values may be beyond modification and adjustment and will never be completely abandoned for others ((Berger \& Luckmann, 1966; Byram, 2003). As a result, tensions and frustrations may occur when students do not experience success in their attempts to assimilate (Gu, Schweisfurth \& Day, 2010). In some extreme cases, some students have committed suicide.

As Dewey (1938) indicated, "all genuine education comes about through experience" (p.14). As researchers and educators, it is our responsibility to provide and share the experiences that will help international students strive and thrive when they are exposed to a foreign culture, however uncomfortable it may be for us and them. This study was inspired by this belief and examined the ways to enhance international students' growth and success in American culture.

\subsection{Literature Review}

Studies showed that challenges such as homesickness and loneliness, the maintenance of self-esteem, time balancing, adjustment to local food and climate, finances, stress, language problems, socialization, and part-time job opportunity 
on campus have been encountered by most of international students (Gu, Schweisfurth \& Day, 2010; Walker, 1999). Also, as Grayson (2008) suggested, many international students are not integrated into many activities of campus life and receive relatively little support from the universities and local community while confronting with difficulties.

Numerous studies outside the U.S. A. have investigated effective ways and programs to help students to survive and grow in a foreign context as more international students are enrolled in universities and colleges (Gu, Schweisfurth, \& Day, 2010; Knight, 2004; Wang \& Li, 2012; Younes \& Asay, 2003). Knight (2004) first came out with the idea that the deepening of international and global connectivity of higher education must be accompanied by and embedded with the history, traditions, culture, and priorities of each student's home country. Wang and Li (2012) from Australia investigated the negative and positive feedback experiences of international doctoral students. They suggested that dialogic and culturally sensitive feedback played critical roles for supervising international students. Further, in the qualitative case study conducted by Younes and Asay (2003), the researchers evaluated the impact of international study on college students. The report indicated that the intercultural communications such as touring in different cultures have powerful effects on participants. Finally, an investigation conducted by three UK researchers explored the complexities of international students' transitional experiences and made comparisons within and across different students in transition to analyze the similarities and differences between students from different academic backgrounds (Gu, Schweisfurth, \& Day, 2010). The researchers pointed out that to help international students adapt within a different educational environment and a different culture and society, universities need to help students in the following three aspects: language mastery which means university programs should help international students develop their skills of reading, speaking writing, and comprehension; social interaction which means university should provide the opportunities to experience culture and environment inside and outside the campus; and academic developments which were related to students' perceived management of the new pedagogy and learning styles.

Moreover, the purposes of adult and postsecondary education lie in the empowerment of individual to be a whole person (Dewey, 1997; Jarvis, 2006; Knowles, 1980) and students' innate needs: survival and growth (Skinner, 1974). Therefore, adult education should emphasize the acquisition of survival skills related to socialization and academic achievements, along with the cooperation and interdependence on organizational, national, even global level because the quest for the good life is still the central task of mankind. Without preparing students with the relative skills and knowledge to survive in the society, the goal of higher education could be hardly achieved (Jarvis, 2006). To reach the above goal for all students, especially international students, scholars have suggested that instructors should help students to pass two critical intercultural adjustments: psychological adjustment (such as psychological well-being or satisfaction that interwoven with stress and coping process) and sociocultural adjustment (such as social skills and cultural learning) (Furnham, 2004; Leung, Pe-Puab, \& Karnilowicz, 2006; Ward \& Kennedy, 1996).

Although considerable attention has been directed to the lives of international students in other countries, there is a lag of research in the U.S. regarding the issues concerning international students. To better help international students adjust successfully in American campuses, there is a need to conduct a research to know current international student's experience.

\subsection{Research Questions}

This study addressed the following questions:

1: What are the challenges and opportunities for international students to learn and grow in American universities?

2: How can administrators and university instructors build a campus environment to help current international students survive and strive in a foreign culture and in doing so, attract more prospective students?

3: To what extent do the quantitative results confirm the qualitative results concerning international students' experience?

\section{Method}

To answer the above research questions, this study adopted a mixed method research design(Tashakkori \& Teddlie, 2003), which is a procedure for collecting, analyzing, and mixing or integrating both qualitative and quantitative at different phases of the research process within a single study (Creswell, 2005). The rationale for integrating both types of data is that neither qualitative nor quantitative data are sufficient by themselves to address the perceptions and details of the situations, such as the complex issue of international students' experience in America. When combined together, qualitative and quantitative methods complement each other and provide a more complete picture of the research problems (Johnson \& Turner, 2003; Tashakkori \& Teddlie, 2003).

In this specific study, the researchers used a sequential exploratory approach (Creswell \& Clark, 2011) to examine the academic and social life of international students in three American universities. There were two phases in the design. The first phase (conducting interviews and initial qualitative analysis) was a qualitative exploration of international 
students' personal experience and stories in studying and living in American universities in which interview transcripts data were collected from 11 students. Because of the lack of relevant instrument and unknown variables to assess international students' experience in American universities, the researchers believed that it was necessary to develop an instrument based on qualitative views of participants. From this initial exploration, the qualitative themes were used to develop survey instrument that was administrated to a large sample. In the planned quantitative phase (reanalysis of the qualitative data, revision and administration of the survey), survey methodology was then used to measure 153 international students' experiences and perceptions of the factors that influenced their lives in three American universities. The reanalysis of the qualitative data and refinement of the survey items were adopted to increase the reliability and validity of this study (Creswell \& Clark, 2011).

The priority in this sequential exploratory mixed methods design was given to the qualitative phase, because 1) the qualitative data collection and analysis were built to quantitative data collection and analysis; 2) the qualitative data analysis was used to develop the instrument to conduct a massive quantitative research (Creswell, Plano, Gutmann, \& Hanson, 2003). The results of the qualitative and quantitative phase were integrated (Creswell et al., 2003) during the discussion of the outcomes of the entire study (See Fig. 1 for a diagram of the mixed methods sequential exploratory design procedures in the study).

\subsection{Participants}

The participants in this study were 153 international students who were studying in four-year universities in America. The four universities were conveniently selected but the surveys were randomly delivered to the participants. The identity of qualitative participants remained confidential from their enrolled programs and colleges (McMillan \& Schumacher, 2001). Participants varied in their nationalities (25 countries) to make sure they were representative enough for the targeted population.

\subsection{Qualitative Interviews}

With the interview questions, the researchers collected qualitative data through 11 (six males and five females) in-depth interviews with a purposeful sample (Patton, 2002) of international students. Participants were selected to present diverse international students' population from five countries (China, India, South Korea, Sri Lankan, and Vietnam) because students from those five countries account for a large percentage of the total enrolled number of international students (NCES, 2011). Each interview was conducted in person, with the length of interviews ranging from 25- 40 minutes. The open-ended questions consisted of general questions about international students' life and their stories on dealing with challenges.

The number of participants was based on Stake's (2006) recommendation of sampling 4 to 10 participants. The researcher reached saturation after roughly seven participants, but conducted a few more interviews to ensure saturation. Moreover, to capture the complexity of information available and to gain insights, multiple transcripts checking, intercoder agreements, and multiple types of data collection (Creswell, 2009; Lincoln \& Guba, 2000) were applied to safeguard the reliability and validity of the study. By collecting and analyzing 11 interview protocols, the qualitative phase relied on inductive reasoning to document emerging themes.

Each interview was audio taped and then transcribed verbatim (Creswell, 2009). Steps in the qualitative analysis included: 1) preliminary exploration of the data by reading and rereading the transcripts and interview journals, 2) coding the data by segmenting and labeling the transcripts, 3) verifying the codes through the peer checking, 4) combining the similar codes together to form the main themes, and 5) connecting and interrelating the themes. Credibility of the findings was secured by exploring different sources of information, member checking, detailed descriptions, and academic advisor's auditing (Creswell, 2009; Merriam, 2009).

\subsection{Survey Instrument \& Data Analysis}

The instrument was designed by building on the themes generated from the qualitative data. Academic experience, socialization experience, navigation among the different cultures, support and assistance from university, and strategies in dealing with challenges are the four independent themes selected to measure the dependent variables of international students experience in American universities. The meaning of the themes was presented in Table 1. A pool of survey items was created for each theme based on the interview data and informed by literature (Fowler, 1993). All the items were pilot tested on $5 \%$ of the selected participants and were tested for alpha reliability. In addition, low-performance items (correlation <.5) were revised, replaced, or eliminated.

The 44 items in the final survey were 5-point Likert-type agreement questions starting from Strongly Disagree to Strongly Agree. All items were stated in the positive. The final section asked four demographic questions. Table 1 presents selected items developed to measure each variable with representative quotations from the qualitative data supporting each one. 
After the development of the survey, a personal pencil-paper collection was conducted with the questionnaire at the library, cafeteria, and student union building.to do. Students were informed that the survey was about their second language learning experience and of their rights as participants. Subsequently, surveys were handed out to interested participants. This was followed by participants' completion of the survey and collection by researchers. After the collection of all the survey data, data were coded and imported into the SPSS. Data were cleaned and re-cleaned to make sure there was no missing data or wrongly inputted data.

Reliability and validity of the survey scales and items were established using descriptive statistics such as mean and range, frequency distribution, internal consistency reliability indexes as well as inter-item correlations (Ivankova \& Stick, 2007). The Cronbach's alpha calculated for all the items was 0.87 .

\subsection{Limitations of This Study}

This study had two limitations. The first limitation was that the selection of the targeted universities was based on a convenient sampling rather than a random one. Another limitation was sample size. Although the response rate was $96 \%$, this study was based on a small sample of 153 . Future study should be conducted on a larger sample with a random sampling.

\section{Results}

\subsection{Qualitative Phase}

The analysis of interview data yielded five themes related to the international students' experience in the American universities: Academic experience, socialization experience, navigation among different cultures, support from university, and strategies in dealing with challenges. Although the researchers interviewed 11 international students, they chose to report five people from five countries (namely China, India, South Korea, Sri Lankan, and Vietnam) for the results for three reasons. The first reason was that they shared more live experiences that covered and reflected the themes merged from all the participants. The second reason was that they represented and met the purpose of this study since we wanted to learn more about the striving and thriving experience of international students. Moreover, they were representative of entire populations enrolled in the universities involved in this study.

\subsection{Quantitative Phase}

The qualitative information collected in Phase 1 served as the basis for the questionnaire, which consisted of a series of measures in a variety of formats. The questionnaire was sent to the international students at three universities randomly $(\mathrm{N}=153)$ from 19 countries and 22 programs. The average years of studying in American university were 1.98 $(\mathrm{SD}=1.26)$. The mean score for class standing were $3.95(\mathrm{SD}=1.41)$. Among the 160 surveys the researchers sent out, a total 153 surveys were returned with a $96 \%$ response rate.

The findings revealed that language and academics are still challenges to most of the international students in the sample. The findings showed that over 53\% of participants thought that language was still a major problem for their study in the America, and over $70 \%$ of participants claimed that academic life such as group work and student-centered learning was still a major challenge, which echoed with the literature (Gebhard, 2010). Participants reported factors that interfered with the learning process and environment. They emphasized that they often need more time to reflect on their learning and to absorb the information and class materials.

Also, although the results indicated that socialization is not a problem, over $50 \%$ of the participants in fact admitted that they spent most of their times with students from their own country. Moreover, over $70 \%$ of the international students believed that the longer they live in America, the more comfortable they would feel in navigating among different cultures, which indicated that they are making efforts to understand and learn how to deal with different cultures in this country.

Concerning the assistance they received from the university, only $45 \%$ reported that their universities or programs offered academic support. Forty percent of the participants reported that their universities have offered various services to help them deal with academic pressure. In addition, 53\% thought the international students' office was helpful.

In terms of the relationship between academic pressure and the ability to function successfully in a foreign culture, the results suggested that there was a significant relationship between pressure and success in adjusting into a new culture, $\mathrm{r}$ $(151)=.67, p<.05$. Also, the results indicated that students' language proficiency significantly correlated with academic success, $\mathrm{r}(151)=.50, \mathrm{p}<.05$, socialization, $\mathrm{r}(151)=.41, \mathrm{p}<.05$, and pressure in a new county, $\mathrm{r}(151)=.49, \mathrm{p}<.05$.

\subsection{Reliability}

The survey included five parts: (a) Academic experience, (b) socialization experience, (c) navigation among different culture, (d) support and assistance from university, and (e) strategies in dealing with challenge. The Cronbach's alpha calculated for the 44 items was .87 , which suggested a high reliability. The items were split into five scales and the 
reliability for the five scales were $.681, .658, .798, .569$, and .892 , respectively, which also indicated a high reliability.

\section{Discussion}

The overall objective of the current study was to explore, describe, and analyze the experience of a sample of international students in American universities in order to identify the factors that might enhance their ability in surviving and thriving in a foreign country. On one level, this study sought to identify and document the endeavors of international students in America who are struggling with schooling, socialization, navigation among different cultures, and getting access to available resources. More than two thirds of the participants reported that academic achievement was the major challenge since their main aim was to get a degree. A number of participants also noted that the universities not only need to provide more services to facilitate international students in adjusting to new cultures, but also need to publicize available resources and services to current and future international students.

On another level, this study's intent was to document and publicize the factors necessary for international students to thrive in a foreign culture. The importance of social skills in navigating amongst various cultures, strategies for dealing with challenges and stress, and sound time management were identified as three critical factors from the qualitative interviews and were measured through the survey results.

\subsection{Striving Experience}

Striving experience (Self-motivation) was identified as one of the significant factors that every international student needs as they strive to settle into a new culture and surrounding. The qualitative and quantitative data findings echoed the limited research on the challenges faced by foreign students in American universities. International students often face the need to adjust as they experience as a decline in social and economic status, separation from family and social supports, a lack of language proficiency, and the feeling of being isolated from their home cultural background (Davey, 2004; Sandhu \& Asrabadi, 1998; Singaravelu \& Pope, 2007). Also, they need to learn socialization skills as they find themselves in a new culture. In essence, how to navigate among different cultures, and most importantly, how to deal with stress.

Although over $80 \%$ of the participants agreed that their decision to study in American universities remained the right one, the findings of this study suggest that the students' experience could indeed be challenging and intimidating without the required support from universities and student advisors. Qualitatively, participants reported that they had no clue on where to get help and who they could rely on for assistance during stressful times. Besides, over $50 \%$ of the participants agreed that they frequently dealt with stress all by themselves. The findings agreed with previous research, which suggested that common problems faced by foreign students in higher education are lack of support, failure to have open communication, and lack of access to information (Davey, 2004).

\subsection{Thriving Experience}

By and large, international students believed that studying in a foreign country is beneficial. These findings are supported by other studies that explored the advantages of studying in foreign countries (Grayson, 2008; Gu, Schweisfurth, \& Day, 2010; Wang \& Li, 2012). Quantitatively, over $80 \%$ of participants indicated that studying in American universities has helped enhance their personal growth and self-discovery. Qualitatively, participants mentioned that studying in American universities provides them with the opportunity to gain new experience and to advance in various aspects of their lives. In addition, studying in the American colleges and universities afforded them the opportunity to enhance their intellectual development because they are exposed to better and improved educational resources and facilities. Also, being independent from parents and other family members helped them to mature and learn important life.

More importantly, the fact that America provides rich experiences and a diverse heritage of multi-lingual, multi-ethnic, and diversified cultures, and students from around the world makes the world as a classroom possible. Therefore, this experience of a global classroom enhances students' awareness of other cultures and teaches them how to interact with people from various backgrounds around the world and how to adapt to changes (Younes \& Asay, 2003).

As Singaravelu and Pope (2007) argued, international students, labeled as nonresident aliens upon their arrival, have encountered adjustment issues and alienation amid their excitement and pride in studying in the United States. Although qualitative and quantitative data alike indicated that international students were working hard to adjust, some research suggested that the obstacles faced by international students may have compounding effects on their adjustments which may ultimately result in academic failure (Brinson \& Kottler, 1995). Therefore, higher education administrator should feel accountable for the success of all students including international students and as such strive to ensure that foreign students' quest for higher education is achievable. 


\subsection{Implementations and Recommendations}

Recognizing that international students' experience in American universities is both challenging and beneficial, the results of this study were aimed at numerous stakeholders: policy makers and higher educational administrators, institutional faculty and staff, and current or future international students pursuing academic degrees in American universities. It is critical for stakeholders to know the factors that may assist or hinder a successful learning experience for international students. The following recommendations are provided to higher educational administrators and institutional faculty and staff to promote international student success.

\subsubsection{Being Culturally Competent when Working with International Students}

Culturally competence, also referred to as cultural sensitivity or cultural proficiency, means a set of congruent behaviors, attitudes, and policies that come together in a system, agency, or among professionals that enable them to work effectively in cross-cultural situations. Culturally competence has been recognized as the most important characteristic of necessary for working with students from diverse racial, ethnic, religious, or social groups (Brown, 2004; Gay, 2000; Guerra \& Nelson, 2007; Ladson-Billings, 1995). Cultural competence guides the values and behaviors of individual leaders so that they may be able to interact effectively in a culturally diverse environment (Guerra \& Nelson, 2007). Both qualitative and quantitative data in this study and research literature suggest that, although faced with obstacles, some international students tend not to seek out support services for fear of being culturally different and not being understood (Zhang \& Dixon, 2003). Furthermore, it is well-known that the most important thing in teaching adult learners is to know your students: who they are and their goals and expectations for what they are taught because most adults come to learning activities for specific reasons (Wlodkowski, 2008). Therefore, administrators, faculty, and staff who work in culturally diverse campuses need to be culturally competent.

There are three ways to become culturally competent. First, administrators, faculty, and staff need to know international students because by knowing the students they work with, they can have a comparatively realistic touch of who they are, and why they enrolled in American universities. Ryan and Viete (2009) discussed principles that international students believe are essential for them to engage in respectful conversations, which promote learning in dialogic, multi-voiced learning spaces. These include feelings of belonging; being valued as a person with knowledge; and being able to communicate effectively, creatively and with confidence. Administrators and instructors in higher education need to stress their respect for diversity and an understanding that people are different as a result of their backgrounds and life experiences (Wlodkowski, 2008). Secondly, they need to work together to build a system of care that acknowledges and incorporates at all levels, the importance of culture. One that celebrates the dynamics that result from cultural differences such as the expansion of cultural knowledge and the adaptation of services to meet culturally-unique needs.

\subsubsection{Affirming Accountability in Higher Education}

As Zumeta (1998) argued, policymakers expect higher education to attain more, costly, sometimes competing goals such as "enrolling a more diverse student population, ensuring high academic standards and ensure adequate job market preparation for students" (p.5). With these accountability goals, higher education needs to build a supporting environment that provides the values, knowledge and skills expected by all students, including international students. Bhandari and Blumenthal (2011) argued, "to some extent, this is about ensuring the quality of a country's higher education system with a view to international achievements, and this is a competitive argument" (p.82). Hence, countries that enroll students from different cultures need to ask what the internationalization of higher education really means and ensure fair access to intentional experience for students from all backgrounds. Moreover, the results of this study and the literature indicated that many international students desire more contact with American students but do not really feel that American students are interested in them (Singaravelu \& Pope, 2007). Therefore, administrators and various students' organizations should make joint efforts to increase awareness and sensitivity to the challenges confronted by the international students. Instructors can do more to create caring, supportive, and inviting classroom settings by encouraging international students to incorporate cultural and international issues into class discussions and presentations.

\subsubsection{Availability of Various Resources}

While living in completely alien cultures, international students are not familiar with resources within universities and local communities. For those who want to seek outside help and support, the universities need to provide them with the support services and networks both on and off campus through orientations and brochures. While striving and thriving in American universities, international students are usually desirous of getting the following information: 1) tips and skills on academic success; 2) how to manage academic and living costs; 3) teaching and assessment methods; 4) counseling information; 5) how to maintain health, welfare, and safety (Davey, 2008; Singaravelu \& Pope, 2007). With the knowledge of and access to the above resources, international students can better adjust themselves into the new environment and live flourishing lives. 


\section{Conclusion}

This mixed method study provided one perspective on the international students' striving and thriving experience in American universities. The results of this study indicated that while benefiting from the oversea study experience, international students face a number of challenges associated with their unique and unfamiliar surroundings. The results and recommendations would be productive for students, institutions, and society since knowledge of international students' experience and how to accommodate them can help international students make sense of what they are experiencing. Such awareness will also help them realize that they are not alone, and provide them with the resources and strategies to address their difficulties.

\section{References}

Berger, P. L., \& Luckmann, T. (1966). The social construction of reality. Harmondsworth, UK: Penguin.

Bhandari, R., \& Blumenthal, P. (2011). International students and global mobility in higher Education: National trends and new directions. New York, Palgrave Macmillan.

Brinson, J. A., \& Kottler, J. (1995). International students in counseling: Some alternative models. Journal of College Student Psychotherapy, 9(3), 57-70.

Brown, D. F. (2004). Urban teachers' professed classroom management strategies: Reflections of culturally responsive teaching. Urban Education, 39(3), 266-289.

Byram, M. (2003). On being 'bicultural' and 'intercultural'. In G. Alfred, M. Byram, and M. Fleming, (Eds.), Intercultural experience and education, (pp.50-66).Clevedon, UK: Multilingual Matters.

Carswell, R. C. (2010). Attracting international students for higher education. New York: Mova Science.

Creswell, J. W., Plano Clark, V. L., Gutmann, M., \& Hanson, W. (2003). Advanced mixed methods research designs. In A. Tashakkori, and C. Teddlie, (Eds.), Handbook on mixed methods in the behavioral and social sciences,(pp.209-240). Thousand Oaks, California: Sage.

Creswell, J. W. (2009). Research design: Qualitative, quantitative, and mixed methods approach (3 $3^{\text {rd }}$ ed.). Thousand Oaks, California: Sage.

Creswell, J. W., \& Clark, V. L.P. (2011). Designing and conducting mixed methods research (2nd ed). Thousand Oaks, California: Sage

Creswell, J. W. (2009). Research design: Qualitative, quantitative, and mixed methods approaches ( ${ }^{\text {rd }}$ ed.). Thousand Oaks, California: Sage.

Davey, G. (2004). The international student's survival guide: How to get the most from studying at a UK university. Thousand Oaks, California: Sage.

Dewey, J. (1997). Experience and education ( $2^{\text {nd }}$ ed.). New York: Touchstone Book. (Original work published 1938).

Fowler, F. J., Jr. (1993). Survey research methods (2nd ed.). Newbury Park, CA: Sage.

Furnham, A. (2004). Foreign students" education and culture shock. The Psychologist, 17(1), 16-19.

Gay, G. (2000). Culturally responsive teaching. New York: Teacher College Press.

Grayson, J. P. (2008). The experiences and outcomes of domestic and international students at four Canadian universities. Higher Educational Research \& Development, 27(3), 215-230.

Gu, Q., Schweisfurth, M., \& Day, C. (2010). Learning and growing in a 'foreign' context: Intercultural experiences of international students. Compare, 40(1), 7-23.

Guerra, P. L., \& Nelson, S. W. (2007). Cultural proficiency. National Staff Development Council, 28(3), 59-60.

Ivankova, N. V., \& Stick, S. L. (2007). Students' persistence in a distributed doctoral program in educational leadership in higher education: A mixed methods study. Research in Higher Education, 48(1), 93-135.

Jarvis, P. (2006). Towards a comprehensive theory of human learning: Lifelong learning and the learning society, volume I. NY: Taylor \& Francis Group.

Johnson, B., and Turner, L. A. (2003). Data collection strategies in mixed methods research. In: A. Tashakkori, \& C. Teddlie (Eds.), Handbook on mixed methods in the behavioral and social sciences(pp. 297-320). Sage Publications, Thousand Oaks, CA.

Knight, J. (2004). Internationalization remodeled: Definition, approaches, and rationales. Journal of Studies in International Education, 8, 5-31. 
Knowles, M. S. (1980). The modern practice of adult education: From pedagogy to andragogy (2 ${ }^{\text {nd }}$ ed.). New York: Cambridge Books.

Lincoln, Y. S., \& Guba, E. G. (2000). Paradigmatic controversies, contradictions, and emerging confluences. In N. K. Denzin \& Y. S. Lincoln (Eds.), Handbook of qualitative research (2nd ed., pp. 163-188). Thousand Oaks, California: Sage.

Ladson-Billings, G. (1995). But that's just good teaching! The case for culturally relevant pedagogy. Theory to Practice, 34(3), 159-165.

Leung, C. R., Pe-Puab, R., \& Karnilowicz, W. (2006). Psychological adaptation and autonomy among adolescents in Australia: A comparison of Anglo-Celtic and three Asian groups. International Journal of Intercultural Relations, 30, 99-118.

Merriam, S. B. (2009). Qualitative research: A guide to design and implementation. San Francisco, CA: Jossey-Bass.

NCES (National Center for Education Statistics). (2009, 2011). Digest of Education Statistics, 2009, 2011, Washington, DC: Institute of Education Sciences, US Department of Education.

Open Doors Data (2011). Retrieved from http://www.iie.org/en/Research-and-Publications/Open-Doors/Data

Patton, M. Q. (2002). Qualitative research and evaluation methods ( $3^{\text {rd }}$ ed.). Thousand Oaks, CA: Sage.

Ryan, Y. \& Viete, R. (2009). Respectful interactions: Learning with international students in the English-speaking academy. Teaching in Higher Education, 14(3), 303-314.

Skinner, B. F. (1974). About behaviorism. New York: Alfred A. Knopf.

Singaravelu, H. D., \& Pope, M. (2007). A handbook for counseling international students in the United States. Alexandria, VA: American Counseling Association.

Stake, R. E. (2006). Multiple case study analysis. New York: Guilford.

Sandhu, D. S., \& Asrabadi, B. R. (1998). An acculturative stress scale for international students: A practical approach to stress measurement. In C. P. Zalaquett \& R. J. Wood (Eds.). Evaluating stress: A book of resource (Vol. 2, pp.1-33). Lanham, MD: Scarecrow Press.

Tashakkori, A., \& Teddlie, C. (2003). The past and future of mixed method research: From data triangulation to mixed model designs. In A. Tashakkori \& C. Teddlie (Eds.), Handbook of mixed methods in social and behavioral research (pp. 671-701). Thousand Oaks, California: Sage.

Wang, T., \& Li, L. Y. (2012). 'Tell me what to do' vs. ' guide me through it': Feedback experiences of international doctoral students. Active Learning in Higher Education, 12(2), 101-112.

Ward, C., \& Kennedy, A. (1996). Crossing cultures: The relationship between psychological competence and social dimensions of cross-cultural adjustment. In J. Pandey, D. Sinha, \& D. Bhawuk, (Eds.), Asian contributions to cross-cultural psychology (pp. 289-306). Thousand Oaks, CA: Sage.

Walker, J. L. (1999). Canada first: The 1999 survey of international students. Ottawa: The Canadian Bureau for international Education.

Wlodkowski, R. J. (2008). Enhancing adult motivation to learn: A comprehensive guide for teaching all adults ( $3^{\text {rd }}$ ed.). San Francisco, CA: John Wiley \& Sons, Inc.

Younes, M. N., \& Asay, S. M. (2003). The world as a classroom: The impact of international study experiences on college students. College Teaching, 51(4), 141-147.

Zhang, N., \& Dixon, D. N. (2001). Multiculturally responsive counseling: Effects on Asian students' ratings of counselors. Journal of Multicultural Counseling and Development, 29, 253-263.

Zumeta, W. (1998). Accountability: Challenges for higher education. Policy Study Review, 15(4), 5-22. 
Table 1. Definitions of Variable and Development of Survey Items

\begin{tabular}{lll}
\hline Themes & Item & \multicolumn{1}{c}{ Supporting Qualitative Data } \\
\hline Academic experience & $\begin{array}{l}\text { Academic life is not a } \\
\text { challenge for me. }\end{array}$ & $\begin{array}{l}\text { Class discussion is still a challenge for me because oftentimes, } \\
\text { I do not know how to better express myself. }\end{array}$ \\
& $\begin{array}{l}\text { Education system is different and it takes time to get used to it. } \\
\text { Compared with my American classmates, I need more time to } \\
\text { Language is not a problem in }\end{array}$
\end{tabular}
my study.

Socialization

Navigation among different I spend most of time with cultures

Support and assistance from university

Dealing with academic, social, I usually deal with stress by and financial stress
I understand class materials

Socialization is not a problem for me in this foreign country. other international students.

I often play games with American students.

I often go to parties to know local people and culture.

My department/college offers academic supports for international students.

My university offers different services to help students deal with pressures.

My university offers some opportunities to help international student to adjust in the U.S. myself.

When feel depressed, I can talk to my friends or counselor.
I know I need some social skills to communicate with local Americans, but I do not how to get them.

I seldom go out and socialize because I am scared of offending people since I do not know their cultures.

If I do have time, I will go to parties with students from my country.

Socialization is really important in America. It can help you to build all the connections.

I spent most of my time with Chinese students and other international students.

My experience is before you go out, you need to know the culture of the people.

I do not really like the fast food culture here and I am not used to the weather here. It is really dry.

You are stranger in this culture and people seldom invite strangers.

Personally, I do not get any assistance from the university.

I think the university staff and administrators just did their routine jobs. They do not provide any additional supports for the international students.

University needs to let international students know where or who they can ask for help through brochures.

I always keep myself positive and tell myself it is not the end of the world.

I usually will ask for help from students from my country if I have any problems.

Listen to my favorite music will cheer me up.

My way of dealing with challenge is easy: being prepared. You got to know there will be challenges when you study in a different culture.

Keep reading and practicing English. 


\begin{tabular}{|c|c|c|c|}
\hline $\begin{array}{c}\text { QUAL } \\
\text { data \& analysis }\end{array}$ & $\begin{array}{l}\text { Instrument builds from } \\
\text { results \& analysis }\end{array}$ & $\begin{array}{c}\text { quan data \& } \\
\text { analysis }\end{array}$ & $\begin{array}{l}\text { Interpretations } \\
\text { and integration of } \\
\text { the QUAL \& quan } \\
\text { results }\end{array}$ \\
\hline *Purposeful sample & ${ }^{*}$ Consider 4 major qualitative & * Administrate survey & * Results describe \\
\hline$(\mathrm{N}=11)$ & themes as variables & $(\mathrm{N}=153$ individuals) & potential factors \\
\hline *In-depth interviews & Develop survey instrument & *Descriptive and & *Interpret the \\
\hline *Transcription & * Pilot-test and refine survey & multiple regression & results to \\
\hline *Coding data & & analyses & understand their \\
\hline *Theme development & & & striving \& thriving \\
\hline
\end{tabular}

Figure 1. Diagram of the mixed methods sequential exploratory design procedures in the study.

\section{(c)) EY}

This work is licensed under a Creative Commons Attribution 3.0 License. 